\title{
CORRIGENDUM
}

\section{A transferable model for singlet-fission kinetics}

Shane R. Yost, Jiye Lee, Mark W. B. Wilson, TonyWu, David P. McMahon, Rebecca R. Parkhurst, Nicholas J. Thompson, Daniel N. Congreve, Akshay Rao, Kerr Johnson, Matthew Y. Sfeir, Moungi G. Bawendi, Timothy M. Swager, Richard H. Friend, Marc A. Baldo and Troy Van Voorhis

Nature Chemistry 6, 492-497 (2014); published online 4 May 2014; corrected after print 21 May 2014.

In the version of this Article originally published, the author name Moungi G. Bawendi was missing the middle initial. This has now been corrected in the online versions of the Article.

\section{CORRIGENDUM}

\section{Ultra stable self-assembled monolayers of N-heterocyclic carbenes on gold}

Cathleen M. Crudden, J. Hugh Horton, Iraklii I. Ebralidze, Olena V. Zenkina, Alastair B. McLean, Benedict Drevniok,

Zhe She, Heinz-Bernhard Kraatz, Nicholas J.Mosey, Tomohiro Seki, Eric C. Keske, Joanna D. Leake,

Alexander Rousina-Webb and Gang Wu

Nature Chemistry 6, 409-414 (2014); published online 23 March 2014; corrected after print 21 May 2014.

In the version of this Article originally published, ref. 40 was incorrect, it should have read: Rodríguez-Castillo, M. et al. Reactivity of gold nanoparticles towards N-heterocyclic carbenes. Dalton Trans. 43, 5978-5982 (2014). This has been corrected in the online versions of the Article.

\section{ADDENDUM}

\section{The importance of being bonded}

Henry S. Rzepa

Nature Chemistry 1, 510-512 (2009); published online 23 September 2009; corrected after print 20 June 2014.

The interactive version of the table shown in Fig. 1 of this Commentary is now additionally available at http://dx.doi.org/10.6084/ m9.figshare.1009626. The online versions of the Commentary have been amended accordingly.

\section{ADDENDUM}

\section{The rational design of helium bonds}

Henry S. Rzepa

Nature Chemistry 2, 390-393 (2010); published online 28 March 2012; corrected after print 20 June 2014.

The interactive version of the table shown in Fig. 1 of this Article is now additionally available at http://dx.doi.org/10.6084/ m9.figshare.1009575. The online versions of the Article have been amended accordingly. 